University of the District of Columbia School of Law

Digital Commons @ UDC Law

2006

Matchmaker, Matchmaker Make Me A Match: An Insider's Guide to the Faculty Hiring Process

Debra R. Cohen

Follow this and additional works at: https://digitalcommons.law.udc.edu/fac_journal_articles

Part of the Education Law Commons, Legal Education Commons, and the Legal Profession Commons 


\title{
Matchmaker, Matchmaker Make Me A Match \\ An Insider's Guide to the Faculty Hiring Process
}

\author{
Debra R. Cohen*
}

\section{Introduction}

You have been thinking about it for a while. Some of your friends have done it. You have decided that it is time for you to act. You create a screen name, list your personal statistics, craft a brief but brilliant responses to standard questions, and publish your profile. While waiting to see who responds to your profile, you search the database seeking potential matches. Perhaps you even send out a few inquiries.

When an e-mail arrives, you feel a wave of excitement. You immediately check the sender's profile. Is this a potential match? Does the sender have the paper credentials you seek? If so, you chat a bit, and if all still seems good, you plan to meet.

The first meeting is often short; a chance to see if there is something more than a paper match. If there is, you meet again to get to know each other better. In time, you may even be invited to take a trip home to meet everyone. If all goes well, the relationship matures into something permanent. If not, having learned something, and added a new friend or story to your life, you continue your search...

The foregoing was a description of internet dating; however, it could just as easily have been a description of a candidate seeking a law faculty position. The process is strikingly similar.

Although not the only method of finding a teaching job, ${ }^{1}$ the Faculty Recruitment Conference

* Associate Professor of Law, University of Massachusetts School of Law - Dartmouth. A.B., 1985, Brown University; J.D., 1988, Emory University School of Law. Thanks to Thomas C. Arthur, Mark D. Bauer, Richard D. Freer, Linda Jellum, Colleen P. Murphy and Ellen Podgor for their comments and support. I would also like to thank the AALS for providing statistical information and my many colleagues who shared their experience both as recruiters and candidates. As promised, except where express permission was obtained, names (schools and individuals) have been omitted.

Before investing the time to read this essay, you might want to know what qualifies me to serve as matchmaker in your search for a law faculty position. I first attended the American Association of Law Schools (AALS) Faculty Recruitment Conference ("FRC") in 1993 and have attended every year since then. I first attended the FRCas a candidate in 1993 and 1994. Like many, I attended twice before finding a tenure-track position. Since then, I have returned to the FRC every year since then, serving as a host in the Women in Legal Education Hospitality Suite and, since 1996, as a small group discussion leader following the Candidate's Workshop. I have spoken with hundreds of candidates, before, during and after the FRC. And, while, due to my aforementioned duties, I have never served as a recruiter at the FRC, I have spoken with many of them and have interviewed many candidates during their on-campus interview.

${ }^{1}$ Other methods used to find a law faculty position include direct application to the school and submission by personal recommendation, usually a law professor or judge. These methods may be preferable to the FRC if you are limiting your search for a law faculty position to a few particular schools. See infra note 37-39 and accompanying text. 
("FRC"), among law professors more commonly referred to as the "meat market," is a mainstay of the faculty hiring process. It is a two and a half day event held annually in October or November in Washington, D.C. ${ }^{3}$ Economists would likely describe the FRC as an efficient use of resources; law schools and candidates gathering in a central location for a limited period of time to conduct preliminary screening interviews. The hiring process, however, begins before the FRC.

It begins when a candidate creates a profile and logs in to complete a Faculty Appointments Register (FAR) form. Though the categories differ, the FAR form, like a dating profile, is designed to provide law schools with concise information in a standardized format for easy searching and selection. While dating profiles focus on personal statistics, the FAR form focuses on academic and employment credentials. While a dating profile lists food and activity preferences the FAR form lists subject matter and geographic preferences.

Completed FAR forms are released to law schools four times annually. ${ }^{4}$ Law schools then search the FAR forms for potential candidates. Law schools select potential candidates and invite them to meet. Meetings are usually thirty minute screening interviews at the FRC. These screening interviews are analogous to a first date. For recruiters, and for candidates lucky enough to have multiple screening interviews, the FRC resembles a marathon speed dating session. ${ }^{5}$

A successful interview at the FRC results in a "call back" for an on-campus interview. In the dating world, this is the equivalent of meeting the family. A successful on-campus interview culminates in the big proposal - a job offer.

This essay traces the faculty hiring process, offering insights and suggestions to help candidates prepare for the process and avoid common pitfalls and mistakes. It is not the only

2 One commentator wrote "Depending upon how cynical you are the conference is referred to as "the Faculty Recruitment Conference," "the Meet Market," or the "Meat Market." Kevin H. Smith, How to Become a Law Professor Without Really Trying: a Critical, Heuristic, Deconstructionist, and Hermeneutical Exploration of Avoiding The drudgery Associated with Actually Working as an Attorney, 47 U. KAN. L. REV. 139, 149 (1998).

3 The FRC is currently held at the Wardman Park Marriot Hotel. For the past decade, it has been held in Washington D.C. Prior to that the FRC was sometimes held in Chicago. A few professors have questioned whether holding the FRC in Washington DC every year creates and East Coast bias. In recent years the FRC has been held the last weekend in October or the first weekend in November, and it has been held as late as mid-November. For the next several years it is scheduled for earlier in October. Dates for the next five years: October 28-30, 2010, October 13-15, 2011, October 11-13, 2012, October 17-19, 2013, October 16-18, 2014.

${ }^{4}$ FAR forms are released to law schools that are members of the American Association of Law Schools (AALS) as well as schools that pay to participate. There are over 200 law schools that might participate in any given year. In recent years some foreign schools have also participated. FAR forms are released approximately one week after each deadline. For more on the timing of the distributions, see infra note 40.

${ }^{5}$ For those unfamiliar with speed dating, one gender sits at a table (here the law schools), and every few minutes (here 30) the other gender (here the candidates) rotate to the next table. At the end of the event, the parties get to indicate who they might like to meet again. If there is a match, the parties meet again. 
foray into the subject, nor is it all-inclusive. ${ }^{6}$ And, like your search for the perfect match, there is no guarantee of success. My goal is simply to help you "date" smart, or at least smarter.

\section{Welcome to Online Dating - The Faculty Appointments Register}

The market for law faculty positions is exceedingly competitive. ${ }^{7}$ In all candor, credentials are critical. Most law professors graduated from an elite law school, served on law review, clerked for a judge and more and more have published before they get to the FRC. ${ }^{8}$ Your FAR form sets forth your credentials. Generally, each year, more than 900 candidates submit FAR forms. ${ }^{9}$ Approximately fourteen percent of these candidates are hired. ${ }^{10}$

In the not too distant past, FAR forms were handwritten or typed, assuming you could find a typewriter. Today they are all online. ${ }^{11}$ You link to http://www.aals.org, click on the Faculty Recruitment Services button and choose the FAR link. ${ }^{12}$

${ }^{6}$ While there are some very helpful articles and websites on the faculty recruitment process, I thought there was room for an update. For other discussions about the hiring process, see Don Zillman, Marina Angel, Jan Laitos, George Pring and Joseph Tomain, Uncloaking the Law School Hiring Process by Professors, 38 J. Legal Educ. 345 (1988) (hereinafter "Uncloaking"); Garbriel J. Chin, Denise C. Morgan (editors) 2002-2004 Michigan J. of Race \& Law Guide For Aspiring Law Professors, 7 Mich. J. of RACE \& L. 457 (2002); Beverly McQueary Smith, Law Teaching: Is it the Next Career for You?, 10 Oct NAt. B. Assoc. Mag. 34 (1996). For a personal account of the process see David W. Case, The Pedagogical Don Quixote de la Mississippi, 33 U. Mem. L. Rev. 529 (2003). For candidates interested in a position as a professor of legal writing, see Jan M. Levine, Leveling the Hills of Sisyphus: Becoming a Professor of Legal Writing, 26 Fla. St. U. L. Rev. 1067 (1999). For candidates interested in fellowship programs see supra note 79. Professor Eric Goldman has a useful web page, called Careers in Law Teaching which includes links to articles, blogs and websites, This page can be found at http://eric goldman.tripod.com/resources/becomingalawprofessor.htm.

7 According to Professor Redding, only about $1.5 \%$ of lawyers teach and only about $0.7 \%$ have tenure track positions. Richard E. Redding, "Where Did You Go to Law School?" Gatekeeping for the Professoriate and its Implications for Legal Education, 53 J. LEGAL Educ. 594, 595 (2003).

${ }^{8} I d$. at 596 ("the prototypical new law teacher graduated from an elite school (most often from Harvard or Yale), was on the staff of the law review or another journal while in law school, clerked for a judge (usually a federal judge), published one or two articles or notes (though many published nothing at all), and practiced for several years (usually in a law firm or a corporate counsel's office) before entering academia.").

9 The AALS publishes statistical reports on candidates for law faculty positions. This data can be found at http://aals.org.cnchost.com/resources statistical.php. Over the past twenty years, the number of candidates has been as high as 1257 in 1993-94 (my first year in the market) and as low as 769 in 2000-01. Between 2002-03 and 2007-08, the number of candidates has ranged from 913 in 2007-08 to 957 in 2003-04. (The data for 2005-06 is not posted).

${ }^{10} I d$. The AALS has not posted success rates for every year. This number is based on the composite 7 year total between 1998 and 2005 as well as the success rate in 2006-07.

11 For those without internet access, or those that do not wish to input the information themselves, the AALS will do it for you for a fee (currently \$50) with an earlier deadline. See http://www.aals.org/frs/faq.php\#2.

12 The direct link for the AALS Faculty Recruitment Services is http://www.aals.org/services recruitment.php. This includes a link to the FAR form as well as 
First, you create a profile - name, contact information and a password, then log in and complete the FAR form. The FAR form contains five sections - Personal, Education Experience, Teaching Experience, Employment Experience, and Bar. It is deceptively simple; most of the information is already on your resume. However, drafting an effective FAR form can be a challenge.

Just like a dating profile, there is limited space for each answer. Condensing your unique experiences into preset sections of between 50 and 255 characters takes time and skill. Luckily, you don't have to complete the form all at once. You can save your profile for later review and editing before publishing it.

Ideally candidates tailor their FAR forms to attract the law schools that appeal to them. Unfortunately, this is difficult because candidates do not know what any particular law school is seeking in any given year. Even if someone were to give you the inside scoop, it could change. ${ }^{13}$ Here are some suggestions for completing your FAR form.

Before publishing a dating profile, many people seek feedback from friends who have had success in the arena. I recommend the same approach here. Before publishing your FAR form, seek input from others who have successfully navigated the process or from those who are on the recruiting side of the process. When possible, seek the opinion of more than one person; it is likely each will offer different suggestions. Just like law school, while there is more than one "right" way to complete a FAR form, there are "wrong" ways.

If you have one, seek feedback from your mentor. Assistance completing your FAR form is just one area where a mentor is helpful. In this process a mentor is a minimum helpful and likely indispensable. If you do not have one, cultivate one. Contact your alma mater. Most schools are excited about having their alumni teach and are happy to assist. ${ }^{14}$

Your academic credentials are exceedingly important. In all candor, graduation from an elite school is definitely advantageous. ${ }^{15}$ However, at this stage, you cannot change where you went to law school. When you complete the Personal Education Experience section, make sure you provide as many details as possible. This includes your actual ranking and percentile ranking, your position on law review and all of your honors.

The Teaching Experience section is your opportunity to set forth your teaching experience and your teaching preferences. Space is provided to list up to four teaching experiences; however only two are labeled as "Law School." The remaining two experiences are labeled "Other." "I In addition to the dates of each experiences and your title, you may select the courses you taught from a menu and include up to 100 characters of other information.

information on the FRC and the placement bulletin. The direct link for the FAR form is http://www.aals.org/frs/far.php.

13 Faculty members have differing views on their school's needs. Additionally, a school's needs may change due to budgetary constraints or departing faculty.

${ }^{14}$ Some schools have faculty or staff designated to help alum through the faculty hiring process. There are the occasional stories to the contrary, but they are few and far between.

15 See supra note 8.

16 Candidates that have more than two "Law School" teaching experiences, often include their additional experiences under the "Other" category. 
Teaching preferences are selected from a menu. You may choose up to three subjects you would most like to teach, and up to four subjects you would be interested in teaching. You may also list up to four subjects you would be willing to teach if asked. This is one of the most important sections of the FAR form as many schools search for candidates based on curricular needs.

As you make your selection, there are a few important things to keep in mind. First, do not make your selection randomly. You should have a reason for listing each course - some connection with your interests or experience. ${ }^{17}$ Further, the courses listed should reconcile with your ideal teaching package. ${ }^{18}$ Second, flexibility is key. Every school must cover its core curriculum. ${ }^{19}$ If possible, include one or two of these classes among your preferences. If, however, you are a specialist, make that clear too. Every school needs at least one tax professor. Third, do not list a course that you would not want to teach, even if you think it is the "hot"course of the year. It is like including your least favorite food as a preference on your dating profile, you will get stuck eating it at some point.

A former legal writing professor suggests that candidates should only list "Legal Research and Writing" or "Clinical Teaching" if these are a primary interest, as it may eliminate the candidate from consideration for "doctrinal" positions at some schools. If you are interested in legal research and writing or clinical teaching, there are additional avenues for pursuing employment, including the Legal Writing Institute website and the Clinical Legal Education Association website. ${ }^{20}$

You may also add a comment up to 255 characters for each subsection. ${ }^{21}$ These comments may be useful for clarifications. ${ }^{22}$ Alternatively, you might want to list a course not included on the menu. For many this is a seminar related to their scholarship.

Finally, you get approximately 100 characters to set forth your geographic limitations. Fifty characters to indicate where you would ONLY accept a position and fifty characters to indicate where you would NOT accept a position. ${ }^{23}$ Essentially, you are being asked if you would

${ }^{17}$ One Professor who had practiced more than a few years before seeking a law faculty position indicated that faculty expected candidates who had been in practice longer to be experts in their area.

18 See infra note 70.

19 As used here, core curriculum means a school's required courses and high demand electives.

${ }^{20}$ For legal research and writing, see Levine, supra note 6 for suggestions. Additionally, see the Legal Writing Institute website for job postings at http://www.lwionline.org/employment listings.html. For clinical teaching, see the Clinical Law Prof Blog at http://lawprofessors.typepad.com/clinic prof/2009/03/job-posting---u.html.

${ }^{21}$ This paragraph is approximately 420 characters.

22 Some choices are very general and you might want to specify a subsection of materials; for example, if you select commercial law from the list, but only want to teach sales, not secured transactions.

${ }^{23}$ One professor requested that I remind candidates not to list Alaska. She recounts being amused each year when, despite the fact that there is no law school there, candidates include Alaska it in their geographical preferences. Another professor suggests being specific as his 
relocate for a match. If so, will you go anywhere or are there limits?

Advice on how to respond to the geographic limitations question covers the spectrum. Some professors suggest you to leave the section blank regardless of your geographic restrictions. This approach allows a candidate to cast a wide screening net and refine the search later in the process. Others suggest you candidly state your preferences. This avoids wasting time and energy on schools located in places you find geographically undesirable.

My advice falls somewhere in between. I suggest you use this section to state unalterable geographic restrictions. If you would not, or could not, seriously consider relocating, indicate this at the outset. This averts the problem of finding an ideal job in a geographically unacceptable location. However, I suggest this only for unalterable restrictions, not for mere preferences. Do not foreclose opportunities solely because you think you would prefer to be in a particular place. You may not be an ideal match for schools in your geographic area of choice. Additionally, you never know when you might find yourself willing to relocate. How many people do you know that have relocated for love?

Under the Employment Experience section you may list up four employers. ${ }^{24}$ For those candidates with more than four previous employees, you must pick and choose. ${ }^{25}$ As you make your choices, remember, employment does not have to be in chronological or reverse chronological order. Highlight experiences that you think will make a hiring committee want to interview you. For example, some professors indicate that judicial clerkships are prestigious and worth including, even at the expense of more recent law firm experience. Again, consult the people reviewing your FAR form for their opinions.

While this section is titled "Employment Experience," it is also where you list your scholarship. The section is titled "Major Published Writings," and you may list up to three items. ${ }^{26}$ I am sure I am not telling you anything new when I say that in legal academia, publishing is preeminent. It is an integral part of law faculty position and schools want to know from the outset that you will be a productive scholar. In fact, there are a number of schools that will not even consider a candidate who has not published.

In all candor, if you have not yet published, you may want to delay submitting a FAR form until you have rectified that FAR form omission. ${ }^{27}$ Also, while opinions on this vary, I caution

definition of "midwest" differed from that of others.

${ }^{24}$ For each employer there is a "You may contact my employer" box. If you have not yet told your employer you are exploring the possibility of teaching, you might not want to check this box. However, please keep in mind that if a law professor knows someone at your employer, he or she may ask anyway.

${ }^{25}$ Remember, if some of them are "Teaching Experiences" you may include them in that section instead. Additionally, you will be attaching your complete resume and the other positions will be included there.

${ }^{26}$ When you list each item, you may where it is published or that it has been accepted for publication. If you designate neither, it will list the item as "not published."

27 Publishing, particularly academic legal scholarship, while in practice can be challenging. In fact, time to reflect and write is often one of the reasons candidates seek a law faculty position. For suggestions on approaching publishing while in practice, see .Rebecca E. Zietlow, Writing Scholarship While You Practice Law, 7 Mich. J. of RACE \& L. 511 (2002); 
reticence about listing works in progress until they are in fairly final form. If you do list a work in progress, be prepared to provide copies when asked.

If, on the other hand, you have more than three publications, you will have to pick the three you want to include on the FAR form. ${ }^{28}$ In making your decision, be aware that schools may attribute different value to different types of publications. ${ }^{29}$ Notwithstanding that, evidence that you will be a productive scholar is essential, and a history of publications is perceived as a good indication of future production. So, even if your publications do not come within the traditional legal scholarship category, if you have space, list them.

In the Bar section, make sure you include your bar admissions. You may list up to three. Some schools look for candidates admitted in their jurisdiction. Some clinical positions require it. Additionally, it demonstrates a connection to the state which is important to some schools. The Bar section is also where you list your references and a statement of additional information describing your qualifications for a law faculty position.

For references, when possible, list law professors and judges who know you and can speak on your behalf. As is always recommended, speak to your references before listing them. You want to include references that are eager to speak on your behalf. Particularly if your references are other law professors, make sure they know why and what you want to teach, as well as something about your research agenda. They will likely be asked.

Next, you state the date you are available to start, and a statement of additional information describing your qualifications for a law faculty position. Some candidates use this section to expand on their scholarship agenda or employment. One caveat - you are limited to 255 characters. Do not to try to cram too much into the space; remember, you are attaching your complete resume.

Finally, before you publish your FAR form, you may upload your complete resume. ${ }^{30}$ Do it! Several professors indicated that a candidate that did not post a resume would be at a distinct disadvantage. It is the equivalent of not posting your photo with your internet dating profile; you would miss out on a number of potential matches. Many schools look at these resumes while deciding whom to interview, particularly for borderline candidates. If possible, rewrite your resume in an academic format, highlighting your teaching experience, scholarship and presentations and service. For samples of academic curriculum vitae, search the law school web sites. ${ }^{31}$ Many are posted.

Tanya K. Hernandez, Placing the Cart Before the Horse: Publishing Scholarship Before Entering the Legal Academy, 7 Mich. J. of RACE \& L. 517 Alternatively, you might want to consider a fellowship program. See infra note 88 and accompanying text.

${ }^{28}$ Remember you will be attaching your resume which contains a more complete list.

${ }^{29}$ Actually different faculty members within a given school may assess different value to different types of publications. Publications can be broadly divided into several categories traditional academic legal scholarship, on-line legal scholarship, practical legal publications, and publications in other areas. Academic legal scholarship can also be subdivided into many categories - including traditional, empirical and narrative

${ }^{30}$ Supported document types include MS Word (*.doc), Text (*.txt), Wordperfect (*.wpd). Make sure the file name does not contain spaces or other non-alphanumeric characters.

31 An easy way to access law school websites is through JURIST. See 
Some final notes on the FAR form. Publish your FAR form in the first distribution to schools, which is traditionally in early to mid August. ${ }^{32}$ This will maximize your opportunities for interviews. Each school has a limited number of slots at the FRC. Many schools start filling their slots immediately. If you miss the first distribution, submit your form not later than the second distribution, which is usually in early September. Many if not most interview slots are filled by the third distribution, and the FRC is long over by the final distribution. While not all schools search the database immediately, it would be unfortunate to miss out on a potential match only because the slots were filled before the school saw your FAR form.

Second, edit your FAR form carefully. Once you publish your form you may only edit the contact information. Make sure the substance showcases your qualifications accurately. Exaggerations have been known to return to haunt candidates. Also, take the time to check for grammatical and typographical errors. Professors report chuckling about them as they continue on to the next form.

\section{The Waiting Game - Part I}

You published your profile in a timely manner; now what? Prepare a dance card ${ }^{33}$ and wait. While waiting to hear from schools, you can access the Faculty Placement Bulletin, where schools place advertisements for positions they are seeking to fill. ${ }^{34}$ As you peruse the advertisements, you might find your dream match. ${ }^{35}$ A school that is the desired status and geography and is seeking to fill a position with teaching preferences that match your ideal teaching package. Should you take "The Rules"36 approach and sit passively waiting for that school to pick notice your form, or should you apply directly?

Opinions on the answer to this question differ. When asked how often candidates were selected for interviews from responses to advertisements, the answers covered the gamut. Some recruiters reported that their schools often select candidates from this pool, particularly local

http://jurist.law.pitt.edu/lawschools/ or the AALS Members page at http://www.aals.org/about memberschools.php.

${ }^{32}$ FAR forms are released four times a year. Check the deadlines for each year. They may get earlier as the AALS is moving the FRC earlier in October. In 2009, the deadlines for submission were August 5, 2009 August 25, 2009, September 15, 2009 and January 21, 2010. FAR forms are distributed to schools about a week after each deadline. The registration fee for publication in the first three 2009 distributions was $\$ 400$. If you registered after September $15^{\text {th }}$ (the fourth publication in February, 2010) the fee was $\$ 435$. While this is after the 2009 FRC, it does include your FAR form in the 2010 distributions. The registration fee also includes a oneyear subscription to the Faculty Placement Bulletin. See supra note 34. the FRC.

33 An antiquated term, but one which describes the process well. It is your schedule for

34 The Faculty Placement Bulletin is distributed four times a year and a subscription is included in your FRC registration fee. Candidates can access the Bulletin online.

35 A school that you find desirable either because it is of its ranking, geographic location or other factor, and is seeking to fill a position that matches your teaching preferences.

36 Ellen Fein, Sherrie Schneider, The Rules: Time Tested Secrets For Capturing the Heart of Mr. Right. (1996). 
candidates. ${ }^{37}$ Other recruiters reported that their schools rarely, if ever, interview from this pool. ${ }^{38}$ With that in mind, respond to the advertisements; it is a second opportunity to get yourself noticed.

Many recruiters reported that their schools interviewed candidates recommended by colleagues. Therefore, when possible, instead of submitting yourself, have a law professor or a judge you clerked for recommend you for consideration. Recommendations from within the legal academy seem to be more effective, particularly when addressed to someone the recommender knows. ${ }^{39}$

FAR forms are released to law schools about a week after each deadline. ${ }^{40}$ Some schools search each distribution immediately. Others wait until after the second distribution to search. Historically schools received printouts and hiring committees had to read through them all to identify potential matches. With the online system, schools now access the FAR online in a searchable database. Fewer and fewer schools still print the forms and review them manually.

Just like an online dating search, each school can set criteria to limit the pool of potential candidates. At most schools, screening of FAR forms is done by committee, and committee members may search by different criteria. Some schools are curriculum driven and immediately limit the pool of potential candidates by subject matter. Other criteria used to limit the pool of potential candidates include demographics, ${ }^{41}$ academic credentials, and publication record. ${ }^{42}$ As with any screening search, the results will be both over inclusive and under inclusive. One graduate of a Canadian law school realized she had been screened out of many searches because she had not attended an ABA accredited law school.

If a school selects you as a potential match, someone from the school will contact you to set up a meeting. Usually this meeting will be at the FRC, however local candidates may be invited to a screening interview at the school before the FRC. Although most schools make contact by phone, an increasing number use e-mail.

When a school calls, engage the caller in a conversation. Ask questions and take notes. This is your first opportunity to learn more about a school that may want to hire you and you can gather information that will help you prepare for your first meeting. Some initial questions include: What position is the school seeking to fill? ${ }^{43}$ Does the school have specific curricular

37 If you are a local candidate, a school may ask you to do a screening interview at the school not at the FRC.

38 Some schools send diversity questionnaires to candidate that apply directly. Whether you complete it is totally irrelevant to whether you will get an interview.

39 One professor reports getting an on-campus interview solely on the basis of a recommendation submitted by her mentor.

${ }^{40}$ For the 2009 FRC, the distributions were August 13, 2009 September 3, 2009 September 24, 2009 and February 2, 2010.

${ }^{41}$ Many schools seek to diversify their population. Diversification includes, but is not limited to gender, race and age.

42 As indicated earlier, some schools use bar admissions to identify candidates with connections to their state.

43 A position might be tenure track, long-term contract or visiting. It might also be a 
needs? ${ }^{44}$ Request information about the school. Today schools direct candidates to their website; however, some schools have brochures on faculty publications and special programs that they would be happy to provide.

Interviews at the FRC are generally conducted between 8:00 a.m. and 6:00 p.m. on Friday and Saturday, though some schools begin on Thursday. ${ }^{45}$ If called early in a school's selection process, you may have your choice of time slots. Professors differ on the ideal time slot. Some professors suggest getting in early in the day before the Recruitment Team is exhausted, others suggest the end of the day so that, as one of the last ones seen, they remember you. Generally I suggest, to the extent possible, a candidate schedule to his or her own strength. If you are a morning person, schedule in the morning.

In any event, if at all possible, do not schedule interviews in back-to-back slots. If an interview is going well, you do not want to be faced with the decision of whether to cut it short, or be late for the next one. ${ }^{46}$ Also, it is good to have a few minutes after each interview to make notes while things are fresh in your mind. Additionally, the FRC is held at a large hotel and, between long corridors and slow elevators, it can take time to get from one interview suite to another.

Candidates often ask what to do if they are invited to meet with a school that they do not think is a good paper match. While some mentors will tell you not to take an interview with a school that does not satisfy your criteria, others will tell you to take all interviews as it may give you negotiating leverage later on. I advocate for the dating approach. If you are certain there is no potential future, do not accept a screening interview. Not only would it waste your time, but it also prevents that school from screening a truly interested candidate. On the other hand, if there is any potential, accept the screening interview and explore the opportunity. ${ }^{47}$ For example, if you would not consider working in New York City, do not schedule an interview with a school located in New York City. However, even if you think NYC is not for you, if you are uncertain, take the interview. My example is geographically based, but it applies to other issues including school status and religious affiliation.

What if the phone is not ringing? Should a candidates attend the FRC if they only have one or two interviews? Can they schedule additional interviews at the FRC? While there are

doctrinal, clinical or legal writing position.

${ }^{44}$ Sometimes schools are not certain of their needs. They do not know if a position will be available, either because they do not know if a faculty member will be returning or if there is funding.

45 Professors report that in addition to gun jumping at the FRC, a number of schools conduct on-campus interviews for particularly coveted candidates before the FRC. Some schools even issue job offers before the FRC.

46 Sometimes candidates have no choice but to schedule back-to-back interviews. If this happens and you are concerned about punctuality, you can leave a note for the later Recruitment Team's chair the night before explaining the situation.

47 If you accept a screening interview but later decide you are not interested in that school, be courteous, contact them to cancel the interview. It will give the school an opportunity to fill the slot with a candidate that is truly interested. 
exceptions to the rule, by the time of the FRC, most dance cards are set. ${ }^{48}$ There may be some minor shuffling, but candidates are not likely to schedule additional interviews at the FRC. ${ }^{49}$

Every year there are candidates who attend despite having only one, if any, interview. ${ }^{50}$ While probability indicates that more interviews increase a candidate's chances of getting a job, in the end, the number of interviews does not matter. It only takes one. Some candidates attend on a fact finding basis. They gather first hand experience on the process, gaining insight into for the next time. ${ }^{51}$ As already indicated, many professors attend the FRC more than once before find a position. ${ }^{52}$

As you prepare for the $\mathrm{FRC}$, keep the dating analogy in mind. If you want a relationship to develop beyond that first date, you not only have to impress a school with how special you are, but you also with your interest in it. Due diligence on each school is imperative.

Schools read your profile, now you should read theirs. Read any materials they sent you and take a good look at their website. Ask your mentor and graduates you know about the schools with which you are interviewing. ${ }^{53}$ Remember, the more you know about a school, the more likely you will have opportunities to engage the Recruitment Team beyond the rote interview conversation. It will also help you prepare questions particular to each school. ${ }^{54}$ Remember Recruitment Teams are sitting through back to back interviews and you want to distinguish yourself.

48 The AALS web site states: "Schools normally prearrange the interviews they will conduct at the Conference. Thus, most schools will have scheduled all or almost all available interviewing time before they arrive at the FRC. ... Few interviews are arranged at the FRC itself. Consider not attending the FRC if you have few or no appointments for interviews." http://www.aals.org/frs/frc.html

49 At the FRC candidates have an opportunity to "drop" resumes and cover letters for schools attending. Many candidates do so with hand written notes; however it does not generally result in interviews at the FRC. Many Recruitment Teams do not even look at the dropped resumes until they have returned to campus. There are, of course exceptions. For example, some newer schools and schools that have unexpected openings may post an announcement at the FRC and screen candidates there. Additionally some fellowship programs have information rooms and conduct informal interviews. You will need your badge to enter the Recruiter's Suite to do this. See infra Speed Dating - The Faculty Recruitment Conference - Logistics. If you plan to do this, I suggest bring copies of your resume with you. It is much less expensive than printing them at the hotel's business center.

50 While not a major economic undertaking if the candidate lives in the Washington, DC metro area, it can become one if a candidate has to travel to attend. In addition to the registration cost and travel costs, the hotel is over \$200 a night. Again, this may give some credence to concerns about an East Coast bias. See supra note 3.

${ }^{51}$ For suggestions on what to do before attending the FRC again, see infra The Waiting Game - Part II.

52 See Case, supra note 6.

${ }^{53}$ When speaking with your mentor, remember they may have connections to that school, like their best friend may be on the faculty of that school, so anything you say may be reported back to that school's hiring committee.

${ }^{54}$ See Infra Speed Dating - The Faculty Recruitment Conference - The Interview Questions for Them. 
Most schools will send you confirmation of your interview, more and more this will come by e-mail. Check your confirmation. ${ }^{55}$ In addition to the time and room, it will often include the names of the members of the Recruitment Team - the portion of the hiring committee that will attend the FRC. If you have this information, use it. Look them up on the school web site or in the Directory of Law Teachers. ${ }^{56}$ One may have gone to your alma mater, or share your teaching preferences or your scholarly interest. It is always good to know when you might be meeting with someone who is an expert in your area of teaching or scholarship.

\section{Speed Dating - The Faculty Recruitment Conference}

While each interview is like a first date, from a macro perspective, the FRC is a marathon speed dating session. Candidates rotate through interview suites every half hour answering substantially the same questions. At the end of the FRC schools choose which candidates they would like to meet again. ${ }^{57}$

While on average more than 900 candidates post a FAR form, only about $55-60 \%$ attend the FRC. $^{58}$ The candidates invited to dance at the FRC have the necessary paper qualifications. The screening interviews provide Recruitment Teams with an opportunity to assess which candidates are likely to be engaging teachers and good colleagues with whom they would want to engage in scholarly debate, work down the hall from, and work with on committees. In a nutshell, they are looking for chemistry - something more than a "paper match." So are you. Screening interviews are a two-way street.

As you move from school to school, remember to be your "best" self. ${ }^{59}$ The you that will captivate and impress the school, distinguish you from the other candidates, and make them want to see you again. Showcase your strengths and talents, but do not promise to be something that you are not. If you do, you may need to pretend a long time in order to succeed.

\section{Logistics}

Every year the AALS opens the FRC with a Candidate's Workshop (the "Workshop"). ${ }^{60}$ The

55 Every year or so there is a candidate who has written down a different time than the Recruitment Team and this creates a great deal of stress as well as missed opportunity as it is often too late to another time.

56 Available on Westlaw. Additionally a copy is available in most law libraries. If you cannot find a person, keep in mind that some schools include a student on their Team.

57 At some schools, the Recruitment Team is authorized to make these decisions at the FRC. At other schools, the decisions are made after the Recruitment Team reports back to the rest of the committee or faculty.

58 This number is based on statistics provided by the AALS. A copy of the e-mail is on file.

59 Professor Linda Jellum - Candidate's Workshop presentation November 2005.

60 The workshop is held on Thursday afternoon between 3:00-6:00. It includes a panel presentation explaining the process and providing helpful suggestions. It is followed by a breakout sessions where candidates have an opportunity to ask questions and garner insights into the process. When you register for the FRC you may elect one of several topics for your breakout session, including general law teaching, teaching after an established career, women in legal education, minorities in legal education and clinical teaching. I have served a leader of one of these sessions for several years. I believe they provide candidates with an opportunity to meet a 
Workshop speakers provide insight into the process. The Workshop is followed by small section discussion groups in areas of the candidate's choice ${ }^{61}$. While many candidates choose to skip this session, candidates who attend report they received helpful insight. I highly recommend that you attend, especially if it is your first time at the FRC. That being said, I am writing this essay, in large part, because much of the information imparted at the Workshop comes too late to be of much use.

There are a number of logistical issues associated with making your FRC successful. First, you must register. Upon registration candidates receive a color-coded badge that identifies them as candidates, a map of the hotel, and a list of schools attending the conference. This list includes the interview room and the names of the professors on each school's hiring committee. ${ }^{62}$ Keep these handy; you will need them.

Take a minute to confirm that the interview room number in your confirmations matches the room number on the list. Rooms have been known to change, and it is much better to clarify in advance rather than miss half an interview after going to the wrong room. Additionally, some schools have more than one interview room. ${ }^{63}$ If your confirmation is not clear, confirm the interview room in which you are scheduled. ${ }^{64}$ Be aware that the FRC is held in a large hotel with several wings and it can be confusing. Consider mapping out your interview journey the night before. Remember that all the candidates are moving at the same time. Elevators can be slow, consider searching out the stairs.

Arrive at each interview punctually. There will be a chair outside the door of each interview room. If the door is ajar, knock to let them know you are there before entering. If not, wait until the appointed time and knock to let them know you are there. While schools try to stay on schedule, sometimes the Recruitment Team will be finishing up with the prior candidate or taking a moment to make notes.

Throughout the FRC, periodically check for messages at the Candidate's Message Center where you registered. If there are last minute changes, schools will often leave a message. Additionally, some schools follow up with candidates at the FRC - with an invitation to a cocktail party, a meal, or even an on-campus interview. ${ }^{65}$

faculty member interested in mentoring new faculty. It also gives candidates an opportunity to meet some of their fellow candidates.

${ }^{61}$ Small section discussion groups provide general perspectives on law teaching. Additionally there candidates can choose to attend a session focused on Beginning Teaching After an Established Career, Clinical Law Teachers, Legal Writing Teachers, Minority Law Teachers, Sexual Orientation and Gender Identity Issues, and Women in Legal Education.

${ }^{62}$ Not every member of a school's hiring committee will necessarily attend the FRC.

63 This often occurs when a school is looking to fill more than one position.

${ }^{64}$ Hopefully the school provided the suite number in the interview confirmation. If not, sometimes schools post the schedule on the door. If not, leave a note for the school the day before. Alternatively, you can stop by one of the room on the hour or half hour and ask.

${ }^{65}$ By the end of a day of interviews, candidates are often exhausted and many have asked if they need to attend the general reception or specific cocktail parties to which they have been invited. As to the general reception, I recommend you stop in and mingle, particularly if any schools indicated they were looking forward to seeing you there. Some schools use this as an opportunity to introduce you to members of their Recruitment Team who might not have been in 
Between interviews, candidates should take advantage of the Candidates' Lounge and the various hospitality suites. ${ }^{66}$ The AALS hosts a Candidates' Lounge where refreshments are provided and faculty members from local schools are available to answer questions about the hiring process. It is also an opportunity to meet your future colleagues. ${ }^{67}$ There are also hospitality suites sponsored by the affinity sections of the AALS - the Section on Minority Groups, the Section on Sexual Orientation and Gender Identity Issues, and the Section on Women in Legal Education. ${ }^{68}$ These suites are also hosted by faculty and each has a discussion panel to answer questions. Additionally, some schools host hospitality suites for their alumni going through the process.

\section{About the Interview}

FRC Interviews, like first dates, come in many shapes and sizes with many personalities. Recruitment Teams range from a single member to more than five. Interview styles run the gamut, from very relaxed and easy going to more formal or even adversarial. The questions, which are discussed in more depth below, may vary, but in the end, everyone, including the candidate, is trying to figure out the same thing. Is there any chemistry? Would this be a good fit? Of course, just like dating, what constitutes a good fit is different for each candidate and school.

While many law professors love meeting the candidates at the FRC, the days are long and exhausting. Unlike candidates, schools do not have the luxury of many breaks. Schools often meet more than thirty candidates during the FRC. Keep that in mind as you enter an interview room, particularly late in the day. Be engaging, make an impression. However, if the Recruitment Team seems slow or disinterested, do not take it personally. It is probably just fatigue.

Not surprisingly, interview questions, like first date conversations, are somewhat predictable. The questions break down into four areas: your credentials, why and what you want to teach, your scholarship, and your questions for them. Be prepared to answer these questions. As the expert on your own credentials, I will comment only on the other three areas.

Teaching: Be prepared to explain why you want to teach. While this may seem an obvious question, not all candidates have actually taken the time to articulate their reasons. ${ }^{69}$ Work with your mentor on this. If possible, tie your reason into your scholarship as "why do you want to teach" is often the broader question of "why do you want a law faculty position."

the room during your interview. This often happens when a school is running more than one interview room. As for cocktail parties or meals to which you were specifically invited, if you are interested in the school, go.

66 The Candidates' Lounge and the hospitality suites are especially useful for candidates not staying at the hotel.

${ }^{67}$ Every year some candidates look at their fellow candidates as their competition and are not willing to socialize with them. That is very unfortunate, as the FRC as many professors report that the FRC is the birth place of many long term friendships with colleagues.

68 Traditionally each section also hosts a question and answer session which can be very insightful. Times are listed on your FRC schedule. If you do not have a conflicting interview, I recommend you attend.

${ }^{69}$ See Uncloaking, supra note 6 at 346. (reporting that at least half of the candidates had not given this question much thought). 
Be prepared to discuss your ideal teaching package and how you would teach these courses. ${ }^{70}$ Your package should include subject matters you listed on your FAR form. Be prepared to explain why you want to teach these classes, how they relate to each other, your scholarship, or your practice experience. ${ }^{71}$ If a school expressed interest in you because your FAR form indicated a particular subject matter, you should include that class in your ideal teaching package. ${ }^{72}$ Additionally, as schools always need to cover the core curriculum, consider including one or two core courses in your ideal teaching package and express a measure of flexibility.

If you are already teaching, you will likely be asked about your teaching experience. This could, among other things, include a discussion on the subject matter, teaching style, or the difference between small and large classes or first year and upper level courses. You may also be asked for copies of any peer or student evaluations. ${ }^{73}$ Do not be defensive if the student evaluations are not all rave reviews. Criticisms like "assigned too much reading" or "too demanding" are not necessarily viewed as negative.

Scholarship: While some candidates have several publications and at least one work in progress, others have not published since law school, have only published in another discipline, or have never published. As a general rule, be prepared to discuss all of your publications. That includes your law school note from years past. Refresh your recollection before you get to the FRC. ${ }^{74}$ Also be prepared to discuss your work(s) in progress and scholarship agenda.

As part of your interview preparation, identify the faculty members from each school who teach and write in your area. ${ }^{75}$ If there are faculty members who have published in your area, familiarize yourself with their scholarship before the interview. If that faculty member is part of the Recruitment Team, you will be prepared for a more substantive exchange, and perhaps convert an interview question into a collegial exchange of ideas. ${ }^{76}$ Remember, even if you do not

${ }^{70}$ A teaching packages is generally comprised of four courses, though at a growing number of schools it may only be three courses. If possible, determine how these courses are taught at each school. For example, Contracts is taught as both a one semester and two semester course and can range in credits from 4-6 credits.

71 See supra notes 17 - 22 and accompanying text. One professor who had practiced for a substantial period before seeking a law faculty position stressed the importance of similarly situated candidates marketing themselves as experts in their designated area.

72 This is one example why notes from the initial contact are so valuable. That being said, recognize that sometimes a school's curricular needs have changed between the time you spoke and the FRC. Also be aware that members of the faculty may disagree on the school's curricular needs.

73 Many candidates bring copies to the conference. If you do not do this, you can offer to send them after the conference. While this does give you a reason to contact the school again, it may not give the Recruitment Team necessary information in a timely manner

${ }^{74}$ Aside from being embarrassing, you are not likely to make a good impression if a if the person asking questions knows your work better than you do.

75 If the school has not sent you their brochure on faculty publications, this information is often available on the school's web page, either on a recent publications page or on the individual faculty web pages. See supra note 31 for links to links of law school websites.

${ }^{76}$ This is an ideal way to distinguished yourself from other candidates, though, be careful 
accept a position at that school, the professors you interview with at the FRC are your future colleagues; people who will read your scholarship and with whom you will exchange ideas.

Those who have not yet published often ask how to proceed. The answer is simple - get started immediately. Scholarship is key. To be successful at the FRC you need to demonstrate that you will be a productive scholar. It would be ideal if you had time to research and write the entire article before the FRC, but for many that is not realistic. At a minimum, by the FRC, you should be able to articulate a scholarship agenda and a starting thesis of an article. ${ }^{77}$ Consider preparing a one page abstract and discuss your ideas with your mentor and others so that they are well articulated. At your interviews, be careful not to overstate the status of your work. If you imply it is all but done, you will be asked for a draft, ${ }^{78}$ or questioned on other articles or cases in the area that you may not yet have had an opportunity to assimilate. ${ }^{79}$

Questions for Them: On a first date, if your date does not express interest in learning about you, you would probably not be interested in seeing him or her again. The same is true at the FRC. If you want a school to believe you are interested in them, ask the Recruitment Team questions about the school and them. However, think carefully about the questions you ask. Avoid questions clearly answered on the school's website or in the materials provided to you. Additionally, keep the first date model in mind. Just as money is not generally a first date topic, salary is not generally a FRC question. What then are good questions to ask?

Specific questions about the school are the best. For example, questions about a particular program or recent event at the school. ${ }^{80}$ If you do not have school specific questions, come to the interview with some good general questions. Some professors suggest asking about research support, others suggest asking about teaching load or quality of students. One of my favorite general question is "What is the most exciting thing on the horizon?" Ask your mentor and professors at your alma mater for good questions.

Candidates always want to know if it is appropriate to inquire about the school's expected hiring schedule. Most professors indicate it is a fair question, and most schools provide this information even if not asked. However, candidates should remember that schedules often

not to ignore the other Recruitment Team members.

77 A scholarship agenda does not require the theses of several pieces. It requires you have chosen an area in which to write, usually an area in which you teach, and have some expertise. You should have some well developed thoughts on the issues you want to address and why they are important. You should also be familiar with the key cases and literature in the area. It is also helpful to have a starting thesis on your first piece. If things go well, you will need to have your ideas developed sufficiently to make a presentation.

78 See supra notes 27 - 28 and accompanying text. As discussed earlier, opinions on this vary. I do not recommend distributing a draft at this state unless the draft is substantially complete and ready for publication.

${ }^{79}$ Candidates have reported experiencing flash backs to law school as they were grilled on alternative theories, opinions and articles in their subject area.

${ }^{80}$ Is the school building a new building? Has it recently created a new program or revamped curriculum? Is the school in a dean search? Additionally, if someone on the Recruitment Team recently published in your area, consider asking about the piece, though only if you are prepared to have a substantive conversation. Also, remember it is an interview; be diplomatic. It might not be an ideal place for vehement opposition to the author's conclusions. 
change.

\section{More Logistics}

Thirty minutes can fly by or seem like an eternity - that in itself tells you a great deal about your chemistry with the school. As you exit each interview, take a few minutes and make some detailed notes. Who was there? ${ }^{81}$ What did you discuss? Were there any questions or issues upon which you would like to follow up? Did you promise to send them something - teaching evaluations, a draft of your article, something else? Like the notes you took at the initial contact, these notes will be helpful if you want to write a thank you note or if the school calls you back for an on-campus interview.

Also note your impressions. For example, did they appear to be a collegial group or did they constantly interrupt each other? Would that bother you? Much though Recruitment Team members try to be on their "first date" behavior too, often you can learn a great deal about faculty dynamics from the interview.

What about thank-you notes? As you might expect, answers to this question run the gamut from "a must" to "not necessary." Thank-you notes can be a nice touch, but only if they are something more than a cookie cutter note. One professor, as a candidate, wrote personal notes to every member of the committee at every school she liked. Many candidates who do write thankyou notes send them only to the committee chair. This may have limited value, as it may not be shared with the rest of the committee. Also, recognize that even if you get them out immediately, call-back decisions are often made before the notes are received.

Three final comments about the FRC. First, over the years I have observed that there are always a few candidates who present themselves as arrogant experts. At the other extreme, there are always a few candidates who upon receiving a candidate's badge, appear to regress to student status. My comment to both is the same. The people you meet at the FRC - both the recruiters and the other candidates - are your future colleagues. Treat them that way.

Second, most candidates seeking law faculty positions are excited about law, but often lack opportunities to discuss it with people who share their enthusiasm. Think of the FRC as meeting with people who share your enthusiasm. Enjoy the opportunity to engage in intellectual discussions about your ideas.

Finally, great interviews do not always result in call-backs for on-campus interviews. Everyone who interviews at the FRC has the paper credentials, and there are many more qualified candidates than there are positions. ${ }^{82}$ Additionally, a number of other factors are often in play - budgetary and curricular restraints as well as faculty politics. As one recruiter reminded me to stress - do not take it personally.

\section{The Waiting Game - Part II}

The FRC is over, now what? You wait. How long? It depends. Call-backs for on-campus

${ }^{81}$ Sometimes the entire Recruitment Team is not present or other faculty member or students are present. Use the list you received at registration to help you recall the names. Be aware that some schools bring a student and his or her name will not be on the list.

${ }^{82}$ For example, In 2003, 957 candidates submitted FAR forms, and 612 of them attended the FRC. Only 143 were successful. Statistics provided by the AALS. 
interviews come sooner than rejection letters; however there are no hard and fast rules. ${ }^{83}$ In recent years, the FRC has been held a few weeks earlier in the semester, and many schools try to conduct their on-campus interviews before the end of the fall semester. ${ }^{84}$ For these schools, callbacks for an on-campus interview may come as quickly as during the $\mathrm{FRC}$ or within days thereafter. Some schools do not know their budget or curricular needs until the spring semester and may not issue their invitations until January or later. Yet other schools have more than one position and will complete one before turning to the other. One professor reports a call-back for an on-campus interviews that came in late February. Generally, if a school has not issued oncampus interview invitations by Thanksgiving, it will not issue them until after New Years. ${ }^{85}$

Call-backs for on-campus interviews are a limited commodity. ${ }^{86}$ If you have been invited for an on-campus interview, the school is seriously interested in you. If you are interested in the school, accept the interview. However, as difficult as it is to turn down an interview when you lack for better options, do not accept an invitation if you would not seriously consider taking the position. On-campus interviews are time consuming and expensive. The legal academy is a small world; if you accept an invitation only to use it as leverage for another position, word may get around.

There are two issues of concern for most candidates. First, what if the call-back is not from the candidate's first choice school. Second, what if the candidate has not received any callbacks?

If you receive an invitation for an on-campus interview, and it is not from your first choice school, it is certainly acceptable to contact other schools with whom you met, particularly if the schools asked you to keep them apprised of your status. Unfortunately, even if other schools are interested in you, they may not be able to expedite their process as quickly as you might need.

Many candidates are discouraged by the silence when they do not receive invitations for oncampus interviews. Some candidates ask whether they should follow up with the schools. In general, no. Silence is its own message. I wish I could tell you that schools will contact you either way. Most will, but not all.

If, at the end of the process, you did not get the opportunities you sought, but truly want to teach, persist. Many professors went through the process more than once before finding a position. Candidates report feeling much better prepared for the process the second time around, and many do get jobs when they return to the FRC. Just like dating, there may be a lot of first dates before finding a serious potential mate.

${ }^{83}$ Rejection letters are generally not sent out until a school completes its hiring process for the year and sometimes they are never sent at all.

${ }^{84}$ Over the next few years the AALS is moving the FRC earlier in October which should facilitate the ability of schools to conduct more on-campus interviews before the end of the fall semester.

85 After Thanksgiving most schools are finishing up the semester and giving exams which makes it difficult to organize on-campus interviews. Most schools resume the interviewing process after the spring semester has begun.

${ }^{86}$ Some schools only invite two or three candidates for each position, other schools may invite as many as four or five. 
Use the interim period to follow up with your mentor or someone you connected with at the FRC. Critically examine your credentials and your FAR form. What gaps do you want to fill? What might you do differently next time. Often, publishing is a key factor. ${ }^{87}$

Some candidates consider a fellowship program designed to give them an opportunity to write and gain teaching experience. ${ }^{88}$ Several fellowship programs interview at the FRC, others have representatives there to discuss their program with potential candidates.

Others consider visiting positions. While you will gain teaching experience from a visiting position, if you are teaching several new courses, the preparation requirements may not leave you much time for your scholarship. Also, be aware that at some schools, visitors are not eligible to apply for a permanent position.

\section{The Courtship}

In many respects, an on-campus interview is analogous to a trip home to meet the family. The faculty will be checking you out, and each faculty member will be assessing you by his or her own standards. Remember it is a two way street; you need to check them out too. Just like dating, it is important that you find a good fit. As you go through the interview, ask yourself if these are people with whom you want to work, and if it is a place at which you want to spend your academic career.

Again, preparation is key and you may not have a lot of time in which to do it. You need to practice your presentation, if possible, multiple times. Ask your mentor to moot your presentation. If that is not possible, take some lawyer friends to dinner and make them moot your presentation. Additionally, before any on campus interview, learn as much as you can about the school. Get on line. Talk to your mentor and professors at your alma mater. Find out what new ventures the school is undertaking. Know what the faculty are doing. Read their work. Pay particular attention to those who teach or write in your area.

The format of an on-campus interview varies from school to school. ${ }^{89}$ A few generalizations: It is generally a one to two day event comprised of formal and informal events, including a presentation, also known as the "job talk." During the interview you will meet a lot of faculty members and answer the same questions multiple times. You will be taken out to eat, but likely will not have much time to eat. ${ }^{90}$ It is exhausting.

${ }^{87}$ For more on publishing while in practice, see supra note 27.

88 Another advantage of theses programs is that they provide mentoring when you go through the faculty hiring process. Teaching fellowships are available at a number of schools. For a list of some of these teaching fellowships, see Michele Goodwin, Fellowships and Fantasies, 7 Mich. J. of Race \& L. 479 (2002). See also http://www.law.arizona.edu/depts/chin/teachlaw/cainfellow.pdf and http://taxprof.typepad.com/taxprof blog/2009/08/fellowships-for.html

${ }^{89}$ For another description of the on-campus interview and the job talk, see Danielle Conway-Jones, A Recruit's Guide to the On-campus Interview Process and the Job Talk, $7 \mathrm{MicH}$. J. OF RACE \& L. 523 (2002).

${ }^{90}$ I always recommend bringing some granola bars or other snacks along as candidates often are so busy answering questions that they do not get to eat much at these meals. 
The professor that invites you to visit campus will generally be your contact person throughout the remainder of the process. Generally this professor supports your candidacy and is a wonderful resource. Make good use of this resource. This professor will provide you information about the format of the interview, and the overall process. Often this professor will also share insight into the people you are meeting and warn you of any traps. Ask questions and listen to the answers.

Candidates are often, and rightfully, most concerned about the presentations. At many schools, the job talk is the most important part of the interview. Candidates usually present a recently published piece or a work in progress. If possible, avoid controversial topics; however, in all fairness it is sometimes surprising which topics are viewed as controversial. If you have more than one option, try to tailor your presentation to the position. For example if you are interviewing for a criminal law position and have a civil procedure article and a criminal law article, present the criminal law article. ${ }^{91}$

Faculty members will use the presentation to gauge a variety of things. Some will use it to assess whether a candidate would be a dynamic teacher. Some use it to judge the candidate's ability to communicate ideas and respond to questions. Still others use it to assess a candidate's scholarly potential - how the candidate thinks about legal problems and engages in legal discourse.

The job talk is usually an hour or less. Ask your contact about the format. Some schools have a set format, others let the candidate set the format. Some schools video tape the presentation so it is available to faculty members that cannot attend the live session.

If you are given a choice, most professors seem to recommend speaking for 20-30 minutes (about half the time) and taking questions afterwards. Assuming that the faculty does wait to ask questions, this will at least assure you a set period to present your thoughts. Also ask your contact about the general nature of the faculty during presentations. Some faculty members are congenial, while others are adversarial. Your contact should also be able to provide insight about the use of technology during a presentation.

Be it adversarial or congenial, think of your presentation as an opportunity to get interesting and possibly helpful feed back on your ideas. ${ }^{92}$ As you do your presentation remember to relax and enjoy it. You are presenting something in which you are interested and in which you are an expert. Remember that and let it show.

Beyond the presentation, you will spend a majority of your time meeting with faculty members. Some of this time will be in formal interviews. At some schools these interviews are one-on-one sessions. At other schools they are group sessions. Either way, you will likely be asked the same questions, many reminiscent of the FRC, time and time again. If you have prepared well, you should be able to expand these conversations beyond interview questions into

91 One professor reports she was told she did not get the position because her presentation was on civil procedure not business associations and the school was seeking a real business organizations person.

${ }^{92}$ Remember every faculty member listens to your presentation through his or her own lens. While this sometimes leads to obscure questions, it can also lead to helpful insights. Also, remember that it is acceptable to respond to a question or comment with "I had not thought about it from that perspective. Did you have thoughts?" 
substantive exchanges. You will also have informal meeting over meals. ${ }^{93}$

During the on-campus interview, candidates often meet with the Dean. The Dean may provide information about salary, title, teaching load, though some of these issues may not be addressed until an offer is made. This is an important meeting. Regardless of whether the Dean votes on hiring decisions, ${ }^{94}$ the Dean has a lot of power and is the person with whom you will likely be negotiating the terms of an offer.

Additionally, at some schools candidates meet with students, ${ }^{95}$ support staff, and university administrators. Finally, in addition to the tour of the facilities, if you are not from the area or the school feels they need to sell you on the location, a tour of the area.

Do not be surprised if some "forbidden" questions are asked before or during your visit. While most law faculty know better, that does not seem to prevent it from happening. In all fairness, when asking these questions, most faculty are not trying to violate EEOC regulations. When they inquire about whether you have a significant other or children they are often trying to engage you in conversation or figure out whether they will need to help your significant other find employment or show you schools for your children. Remember, the school liked you enough to invest time and money in bringing you to campus. They want to sell you. If they offer you a job they want you to accept.

\section{The Proposal - What To Do Before You Say "I Do"}

Congratulations! You have been offered a job. You may not have long to decide. Schools often give candidates "exploding" offers - a very short time in which to make a decision. There are two reasons for this. First, schools do not want candidates to use their offers to generate other offers. Second, in the event that the first choice says no, the school does not want its second choice to feel like second choice.

If the school does not appear to be a good fit, think long and hard before you accept it. Every year candidates are faced with a choice of accepting a position that is not an ideal fit or not entering legal academia. It is a difficult decision. One professor reports turning down the position and returning to the FRC another year only to find a better fit. Other professors report accepting the position, only to return to the market seeking a lateral position. ${ }^{96}$

If the school appears to be a good fit, before you say I do, I recommend you negotiate. You are in your strongest negotiating position during the post-offer, pre-acceptance window. Below are some issues you might want to consider before accepting. I also recommend you speak to your mentor about these and other issues.

93 See supra note 90.

94 At many schools, the Dean only votes in the event of a tie.

95 One school has asked candidates teach a mock class.

${ }^{96}$ Sort of like accepting a proposal of marriage because you are more focused on getting married than the person you are married. Often these couples wind up divorced. Many candidates accept a position assuming they will be able to move laterally. Do not make this assumption. Professors report that lateral moves are by no means an assured event. Speak with your mentor about this. 
Money: Information on salaries is somewhat limited. The information at a state university is usually public; and the Society of American Law Teachers does an annual survey on law professor salaries. ${ }^{97}$ Some schools will hire a candidate with prior teaching experience or many years of practice experience as an associate professor as this often allows a slightly higher salary. Several Deans have reported that salary is one area where they lack flexibility. However, they often have leeway in other areas, like one time expenditures like relocation expenses, house hunting trips and pre commencement summer stipends.

Research Support: Many schools offer summer stipends to promote scholarship. Inquire as to how these stipends are awarded and when you are eligible for one. If your research requires travel, consider requesting additional travel funds. Also inquire about the availability of and funding for research assistants. At some schools research assistants are paid from the faculty member's research and travel budget. At other schools research assistants are funded separately.

Course Package: Negotiate which courses you will be teaching. At most schools the teaching load is between ten and fourteen credits a year, but at some schools it may be even fewer. If you are new to law teaching consider asking for a light load (only one course) your first semester. If you are preparing several courses during your first years of teaching consider asking for a repeater course (a course offered in the fall and repeated in the spring semester) so that you do not need to prepare two courses at one time. Also consider asking for a limit on the number of new preparations during the pre-tenure years.

Service assignments: Some schools provide a reduced committee assignment the first year or during your pre-tenure years. At every school, some committees are more political than others. Until you have had an opportunity to learn the lay of the land, try to avoid the political committees. ${ }^{98}$

Credit for previous teaching and scholarship: Inquire regarding policies for credit, if any, you will receive for prior law school teaching experience or publications. While some schools will give credit for title and salary, some faculties are resistant to giving credit toward tenure. Research the issue with your mentors and future colleagues.

Faculty Handbook: request a copy of the faculty handbook, and if separate, the retention, promotion and tenure rules. Read them. Know what is expected for success. The faculty handbook will include all sorts of helpful information.

As a final note, I suggest you get your negotiated terms in writing. Deans come and go. You want the deal documented.

\section{Conclusion}

What happens after you say "I do" is the topic of another essay. So, I will end with a two brief thoughts on life after "I do." First, you do not have to do it all in your first year. This is a marathon, not a sprint. Second, you do not have to reinvent every wheel. There are numerous resources available to new law teachers. For example, every summer the AALS sponsors the

97 See http://www.saltlaw.org/contents/view/salarysurvey.

98 Admissions, Appointments and Curriculum tend to be political committees. 
New Law Teacher's Workshop. ${ }^{99}$ The AALS also has a section for New Law Professors. ${ }^{100}$ There are numerous online resources including list serves and blogs as well as law review articles. Finally turn to your law school mentor, the friends you made at the FRC, and your new colleagues. Use them.

Like your search for the perfect match, the process of finding a law faculty position will likely have its ups and downs. You may have to kiss a few toads along the way. However, the bad interviews make wonderful stories and the good ones create wonderful friendships and careers.

${ }^{99}$ For more information on this workshop, see http://www.aals.org/events nlt.php

100 For the section website, see http://www.aals.org/services sections nl.php. 